\title{
EFFECT OF CENTRIFUGAL SPEED ON THE ANTICORROSIVE PROPERTIES OF BISMUTH-SILICON COATINGS BY SOL-GEL ON 316L SUBSTRATES
}

\author{
J. Bautista-Ruiz ${ }^{1, *}$, W. Aperador ${ }^{2}$ and J.J. Olaya ${ }^{3}$ \\ ${ }^{1}$ Department of Electromechanical Engineering, Universidad Francisco de Paula Santander, San \\ José de Cúcuta, Colombia \\ ${ }^{2}$ Universidad ECCI, Bogotá, Colombia \\ ${ }^{3}$ Department of Mechatronic Engineering, Universidad Nacional de Colombia, Bogotá, \\ Colombia \\ *E-mail : jorgebautista@ufps.edu.co
}

\begin{abstract}
In this investigation, the compound $\mathrm{Bi}_{24} \mathrm{Si}_{40} \mathrm{O}_{2}$ was synthesized via sol-gel and applied on substrates of $316 \mathrm{~L}$ stainless steel by spin coating varying speed. In the coatings obtained, the corrosion response in simulated physiological solution was evaluated by electrochemical impedance spectroscopy and polarization potentiodynamic curves. The morphology and surface topography was studied, also, were determined the microstructure, thickness values and roughness of the coatings. The results of this study allow establishing a high degree of anticorrosive effectiveness offered by the coatings as a function of the number of layers applied to the substrate and their possible application in the biomedical industry.
\end{abstract}

Keywords: anticorrosive properties, sol-gel, bismuth-silicon, biocompatibility.

(C) RASĀYAN. All rights reserved

\section{INTRODUCTION}

The Sol-Gel method has been used in last years to design a great variety of materials. This method is highly implemented because the process takes place at room temperature. Likewise, another important factor in the sol-gel method is the preparation of materials with high purity and variety of compounds. This process has been used to design new ceramic and composite systems with specific properties fitting within the lowtemperature co-fired ceramics technology better known as LTCC.This technology has had advantages compared to other technologies, for example, the ceramics are sintered at temperatures below $900{ }^{\circ} \mathrm{C}^{1}$.

Metals are part of the basic equipment of most of the industrial fabric, including very diverse segments such as the oil, chemical, automotive, construction, and health industries. However, the steels are susceptible to corrosion phenomena due to chemical or electrochemical reactions, with the consequent deterioration of their properties limiting their life in use and losing efficiency in the applications to which it is destined, leading to a technological, economic and of health ${ }^{2,3,4}$.

Among the metals, it is important to apply the steels as the AISI 316L which is commonly used in food preparation equipment, especially in chloride environments; chemical processing, equipment; laboratory benches and equipment; rubber, plastics, pulp and paper machinery; pollution control equipment; boat fittings, value and pump trim; heat exchangers; pharmaceutical and textile industries and condensers, evaporators and tanks ${ }^{5,6}$. In addition, stainless steel $316 \mathrm{~L}$ is useful in surgical implantology, for its economy in costs compared to other conventional materials such as titanium. Steel implants are considered a health problem due to the risks that their degradation entails in the body of treated patients ${ }^{7,8}$. The implanted steel is subjected to corrosive conditions generated by the physiological fluids of the body. This situation allows dissolved iron to diffuse into the patient's body causing the tissues in contact to be damaged ${ }^{9,10}$.

One of the possible solutions to the problems of corrosion of the steels used in implantology, is through the superficial modification of the substrate by the application of coatings that are biocompatible. The compounds with the formula $\mathrm{Bi}_{12} \mathrm{MO}_{20}\left(\mathrm{M}=\mathrm{Si}, \mathrm{Ge}, \mathrm{Ti}, \mathrm{Pb}, \mathrm{Mn}, \mathrm{B}_{1 / 2}, \mathrm{P}_{1 / 2}\right)$, called sillenites, can be

Rasayan J. Chem., 11(2), 597 - 607(2018)

http://dx.doi.org/10.31788/RJC.2018.1122075 
considered as promising materials for the development of LTCC technology. The Sol-gel synthesis offers potential advantages over traditional solid-state synthesis methods. In addition, it allows a precise control on the composition, the homogeneity and the deposition of the coatings ${ }^{1}$.

The results of investigations by the sol-gel method for the synthesis of films have been reported, for example, Cheraghi et al. deposited $\mathrm{TiO}_{2}-\mathrm{NiO}$ nanocomposite films on substrates at various concentrations for the anticorrosive application. The authors found that the best anti-corrosion response is obtained from the concentration $80 \% \mathrm{TiO}_{2}-20 \% \mathrm{NiO}^{11}$. In order to expand the knowledge regarding clinical applications via sol-gel on stainless steel $316 \mathrm{~L}$, Sidane et al. suggest the application of the first layer of titanium oxide $\left(\mathrm{TiO}_{2}\right)$ on the stainless steel substrate. The titanium oxide film improved the corrosion resistance and mechanical properties of the HAP coating system and $316 \mathrm{~L}$ stainless steel. The results of the investigation established that the $\mathrm{TiO}_{2}$ films increase the degree of homogeneity, the crystallinity rate of the system and was determined their mechanical properties. The results showed the possibility of using such a coated material as a replacement material for hard tissues ${ }^{12}$. Salahinejad et al. report the use of both inorganic and organic-inorganic coatings on stainless steel substrates. They deposited films of $\mathrm{ZrTiO}_{4}$ as the lower layer and $\mathrm{ZrTiO}_{4}-\mathrm{PMMA}$ as the top layer. The results show that the corrosion resistance is related to the good adhesion of the lower inorganic coating and to the low density of upper film defects ${ }^{13}$. Although, the solgel method has proved to be effective, fast and economical and there are no reports related to the synthesis of bismuth-based films and compounds applied on 316L stainless steel.

Materials as silicon oxide $\left(\mathrm{SiO}_{2}\right)$ can improve the corrosion resistance of metals at different temperatures, because of its high thermal and chemical resistance ${ }^{14} \cdot \mathrm{Bi}_{2} \mathrm{O}_{3}$, have attracted great attention due to a high refractive index, electrical permissiveness, photoconductivity, photoluminescence, and a wide energy gap ${ }^{15}$. They are also important in the manufacture of transparent ceramic glass, optical coatings, and ceramics, among others ${ }^{16,17}$. Recent studies have not reported results with respect to anticorrosive coatings Bismuth - Silicon on 316L stainless steel substrates by Sol-gel method. For this reason, the aim of this paper is the synthesis and evaluation of $\mathrm{SiO}_{2}-\mathrm{Bi}_{2} \mathrm{O}_{3}\left(\mathrm{Bi}_{\mathrm{x}} \mathrm{Si}_{\mathrm{y}} \mathrm{O}_{\mathrm{z}}\right)$ thin films using the sol-gel spin coating technique, taking advantage of each of the components as an alternative for improving the corrosion resistance of the 316L. The anticorrosive study was developed with a simulated physiological solution (Ringer's solution), using the techniques of Electrochemical Impedance Spectroscopy - EIS and Potentiodynamic Curves. The results were compared with those obtained in uncoated steel specimens, as a function of the variation of the speed of production by the centrifugation technique. To complement the research, it was decided to study, additionally, the surface morphology and topography by the techniques of Scanning Electron Microscopy - SEM, Atomic Force Microscopy - AFM; microstructure using X-ray diffraction and, the measurement of the thickness and the roughness of the films. It is concluded that the anticorrosive effectiveness of the coatings is directly related to the spin speed.

\section{Material and Methods}

\section{EXPERIMENTAL}

All chemicals brand Aldrich-98\%. The chemicals used in this study were:

1. Tetraethyl orthosilicate and bismuth nitrate (III) pentahydrate as precursors

2. 2-Ethoxyethanol and glacial acetic acid as solvents, and

3. Ethanolamine as a complexing agent.

In this synthesis, the methodology proposed by Veber ${ }^{1}$ was modified. Initially the amount of bismuth nitrate pentahydrate $(10 \mathrm{~g})$ is dried for 96 hours at $65^{\circ} \mathrm{C}$ in a vacuum oven, decreasing the amount of water in the system. A solution is prepared with the dehydrated bismuth nitrate dissolved in $25 \mathrm{ml}$ of acetic acid under stirring for 2 hours. Another solution is available with TEOS and 2-ethoxyethanol under stirring for 30 minutes. 2-ethoxyethanol is the solvent for TEOS. For this work the molar concentration of TEOS was 0.75 based on research developed by Veber ${ }^{1}$. After the stirring time of the two solutions has elapsed separately, they are mixed and left in magnetic stirring for another three hours. At this point, with ethanolamine the $\mathrm{pH}$ is adjusted to a value of 4 , necessary for getting films. To obtain good miscibility of the precursors, and thus good homogenization of the solutions, they were mixed using magnetic stirring at $300 \mathrm{rpm}$. Finally a 
stable and homogeneous sun is obtained. Afterward it is allowed to leave it aging for 500 hours favoring the conditions necessary for its application as a coating.

For the development of this research, a commercial AISI 316L stainless steel with the following composition (in\% by weight) was used as substrates Fe-16.42 Cr-11.24 Ni-2.12 Mo-0.020 C-0.37 Si-1.42 Mn-0.011 S-0.040 P, and with dimensions of $3.5 \mathrm{~cm} \times 2.5 \mathrm{~cm} \times 0.32 \mathrm{~cm}$. The selected steel sheets exhibit porosity defects typical of the manufacturing process. Any imperfection on the surface of the substrates had great implication in the final quality of the coatings, such as poor adhesion, cracks and pores. The process of preparation of the substrates was carried out in four steps, (1) the AISI / SAE 316L steel substrates were initially subjected to a mechanical polish using as the abrasive surface, in the sequence given below, 80 , $120,200,220,320,400,600,1000$ and 1200; the residence time of the substrate in the polishing phase depended on the number of defects present on its surface. (2) The substrate was polished with metallographic gloss using a cloth impregnated with a solution of water and alumina of granulometry 0.3 $\mu \mathrm{m}$. (3) Cleaning step in an ultrasound device starting with distilled water, continuing with acetone and finally with propanol; the residence time of each substrate per cleaning solution was 5 minutes, and (4) Oven dried for 10 minutes at $80{ }^{\circ} \mathrm{C}$ to allow evaporation of the solvents used in the previous step.

\section{General Procedure}

To obtain the ceramic coatings was used a spin-coater equipment. In Table-1, the type of sample and the rotation speed are related.

Table-1: Sample nomenclature and Spin speed
\begin{tabular}{c|c} 
Sample & Spin Speed (rpm) \\
\hline S1 & 1500 \\
\hline S2 & 2500 \\
\hline S3 & 4000 \\
\hline
\end{tabular}

The sintering step of the films is important because the final properties of the coating such as uniformity, adhesion, the degree of pore formation and cracking in the coating depend to a great extent on this parameter. Once the coatings are formed in the spin-coater the samples were transferred to the drying stage at $65^{\circ} \mathrm{C} / 24 \mathrm{~h}$, to eliminate solvents. Then were sintered at a heating rate of $1{ }^{\circ} \mathrm{C} / \mathrm{min}$, from room temperature to $215^{\circ} \mathrm{C}$ it is kept constant for 2 hours and again brought to a temperature of $400{ }^{\circ} \mathrm{C}$ it stabilizes one hour and allowed to cool to room temperature.

\section{Detection Method}

Electrochemical Impedance Spectroscopy (EIS) tests were developed in a three-electrode cell: $\mathrm{Ag} / \mathrm{AgCl}$ reference electrode; Platinum electrode as a counter electrode; Working electrode substrate-coating system with an exposure area of $1 \mathrm{~cm}^{2}$. The analysis solution was Riger's solution. Frequency ranges from 0.01 $\mathrm{MHz}$ to $100 \mathrm{kHz}$. Scanning potential of $10 \mathrm{mV}$. The EIS data were analyzed by fitting to a proposed equivalent electrical circuit model and constituted by capacitances and resistances, with the Gamry Echem Analyst software with the nonlinear method of least squares method based on iterations.

In the polarization tests, a cell of three electrodes was used, using an $(\mathrm{Ag} / \mathrm{AgCl})$ electrode as a reference electrode, and one of platinum as counter-electrode. The exposure area was $1 \mathrm{~cm}^{2}$, scanning speed of 1 $\mathrm{mV} / \mathrm{s}$ with immersion in Ringer's Solution. The sweep potential range ranged from $-0.200 \mathrm{mV}$ to $200 \mathrm{mV}$. Speeds and corrosion potentials were obtained by Tafel extrapolation using a GAMRY Instruments potentiostat-galvanostat. The analysis of results was carried out using the Echem Analyst program. The resolution of equipment was of $20 \mathrm{~V}$ and $1 \mathrm{fA}$. Three potentiodynamic tests were developed for each coating. The values of corrosion potential (Ecorr) and corrosion current density (icorr) were determined by the Tafel extrapolation method using the Gamry Echem Analyst software version 5.3. The surface characteristics of the coatings were studied by Nanosurf atomic force microscopy (AFM) in tapping mode. In the characterization of the surface morphology and its elemental composition, a scanning electron microscope (COXEM-200m) and an X-ray spectral analyzer (EDAX) were used. In the microprobe analysis, the composition of the elemental was determined by the average of 5 areas of $300 \times 200 \mu \mathrm{m}^{2}$ randomly selected. 
The depth of the analysis was up to $5 \mu \mathrm{m}$. In the determination of the crystalline parameters, a PanalitycalEmpyream diffractometer was used in Bragg-Brentano geometric configuration with copper $\mathrm{K}_{\alpha}$ line (1.540998 $\AA$ ), current of $30 \mathrm{~mA}$, potential difference of $40 \mathrm{kV}$, sweep from $20^{\circ}$ to $90^{\circ}(2 \theta)$, step time of $0.50 \mathrm{~s}$ and step size of $0.020^{\circ}(2 \theta)$ in continuous mode. In the measurement of thicknesses, a DEKTAK 150 profilometer with $6 \AA$ repeatability, valley and ridge profile, $600 \mu \mathrm{m}$ scan, $30 \mathrm{~s}$ time, $1 \mathrm{mg}$ force and 0.067 $\mu \mathrm{m}$ resolution / sample was used.

\section{RESULTS AND DISCUSSION}

Figure-1 shows $\mathrm{SEM}$ micrographs of $\mathrm{Bi}_{x} \mathrm{Si}_{\mathrm{y}} \mathrm{O}_{z}$ coatings at three study speeds and deposited on the AISI 316L stainless steel substrate. The obtained coatings are detailed at speeds of $1500 \mathrm{rpm}, 2500 \mathrm{rpm}$ and 4000 rpm, Figure-1a, Figure-1b and Figure-1c respectively. All the micrographs were taken at 1000X. Irregular surfaces are observed with the predominance of white and dark areas. The white areas correspond to the growth of bismuth and silicon oxides, due to the sintering process of the films. Dark areas correspond to consolidated films. In this same graph the morphology of the oxides (white zones) can be appreciated, its size varies according to the speed with which the coatings were formed, that is to say, for speeds of obtaining $4000 \mathrm{rpm}$ (Figure-1c) Greater agglomeration of the oxide with a smaller size of them. This can be attributed to the centrifugation process and consequently to the final thickness of the coatings, and also according to the investigations of Rajabi-Zamani and Feng the agglomerated structures observed in micrographs of Figure- 1 are due to the aging or gelation time of the soles from which the coatings were formed $^{18,19,20}$.
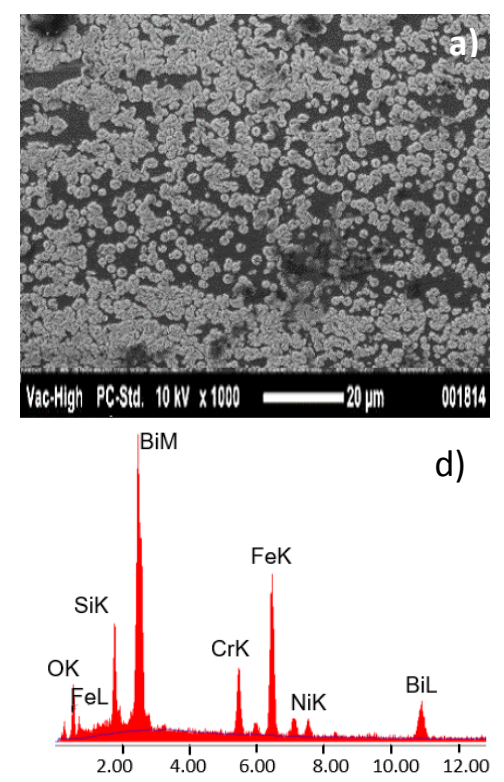

Fig.-1: SEM and EDX results for $\mathrm{Bi}_{\mathrm{x}} \mathrm{Si}_{\mathrm{y}} \mathrm{O}_{\mathrm{z}}$ system coatings.
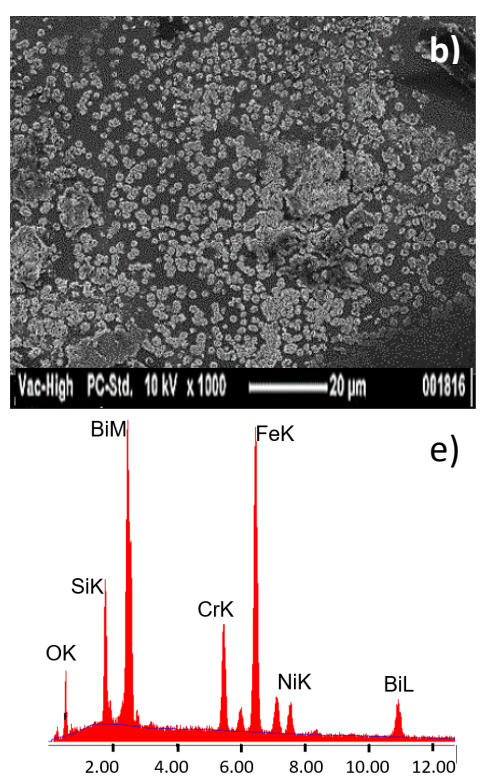
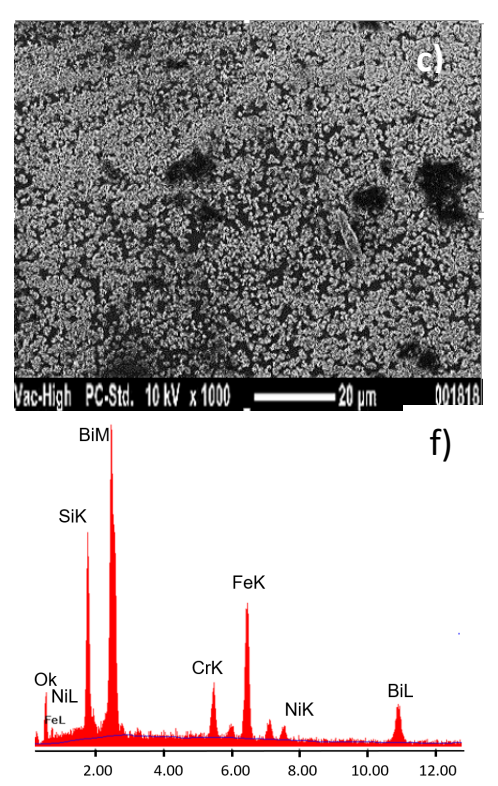

f)

Through the results of dispersive energies (EDX) it is possible to determine the composition of the oxides. If the pattern of parts $d, e$ and $f$ of Figure- 1 is observed, the existence of oxides of bismuth and of silicon, mainly of bismuth, is revealed; as shown by the percentages by weight obtained from each of the elements present in the coatings recorded in Table-2. Also, elements such as $\mathrm{Fe}, \mathrm{Cr}$ and $\mathrm{Ni}$ corresponding to the composition of the substrate 316L appear. The manifestation of these last elements in the energy pattern shows the thinness of the films of the $\mathrm{Bi}_{x} \mathrm{Si}_{y} \mathrm{O}_{z}$ system obtained by Spin-coating.

From the results of thickness measurements for the films it was found that coatings S1with a value of $390.88 \pm 0.21 \mathrm{~nm}$. S2, $314.36 \pm 0.65 \mathrm{~nm}$ and at S3 $290.57 \pm 0.41 \mathrm{~nm}$. The effect of the forming speed on the final thickness is evident. Low spin speeds for film growth allow thicker coatings to be obtained in comparison to high spin speeds with which films with lower thicknesses are achieved. Figure- 2 corresponds 
to the results obtained by AFM of the surface characteristics of the substrate $316 \mathrm{~L}$ and $\mathrm{Bi}_{\mathrm{x}} \mathrm{Si}_{\mathrm{y}} \mathrm{O}_{\mathrm{z}}$ system films. To facilitate the comparative analysis, representative areas of $45 \mu \mathrm{m}$ x $45 \mu \mathrm{m}$ were taken.

Table-2: Percent by weight of the constituent elements of the coatings and the substrate Sample

\begin{tabular}{c|c|c|c|c|c|c|c|c}
\hline \multicolumn{3}{|c|}{ S1- 1500 rpm } & \multicolumn{3}{c|}{ S2- 2500 rpm } & \multicolumn{3}{c}{ S3- 3000 rpm } \\
\hline \multirow{2}{*}{ Element } & $\begin{array}{c}\mathrm{Wt} \\
\%\end{array}$ & $\begin{array}{c}\text { At } \\
\%\end{array}$ & Element & $\begin{array}{c}\mathrm{Wt} \\
\%\end{array}$ & $\begin{array}{c}\text { At } \\
\%\end{array}$ & Element & $\begin{array}{c}\mathrm{Wt} \\
\%\end{array}$ & $\begin{array}{c}\text { At } \\
\%\end{array}$ \\
\hline $\mathrm{OK}$ & 11.22 & 39.69 & $\mathrm{OK}$ & 7.82 & 27.94 & $\mathrm{OK}$ & 10.27 & 36.21 \\
\hline $\mathrm{SiK}$ & 6.42 & 14.01 & $\mathrm{SiK}$ & 7.13 & 14.51 & $\mathrm{SiK}$ & 11.58 & 23.26 \\
\hline $\mathrm{CrK}$ & 5.60 & 8.03 & $\mathrm{CrK}$ & 9.23 & 10.15 & $\mathrm{CrK}$ & 5.18 & 5.62 \\
\hline $\mathrm{FeK}$ & 21.53 & 21.25 & $\mathrm{FeK}$ & 31.35 & 32.08 & $\mathrm{FeK}$ & 17.95 & 18.13 \\
\hline $\mathrm{NiK}$ & 2.68 & 3.16 & $\mathrm{NiK}$ & 4.53 & 4.41 & $\mathrm{NiK}$ & 2.78 & 2.67 \\
\hline $\mathrm{BiL}$ & 52.55 & 13.98 & $\mathrm{BiL}$ & 39.93 & 10.92 & $\mathrm{BiL}$ & 52.23 & 14.1 \\
\hline
\end{tabular}

a)

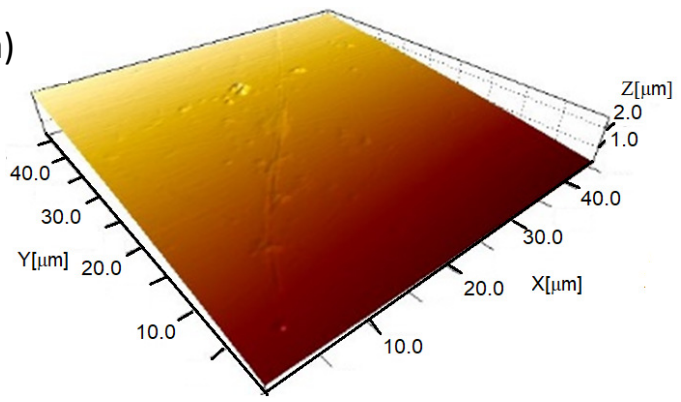

c)

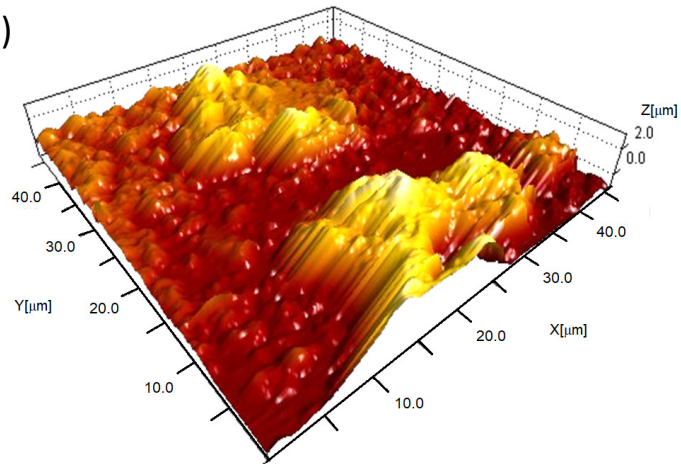

b)

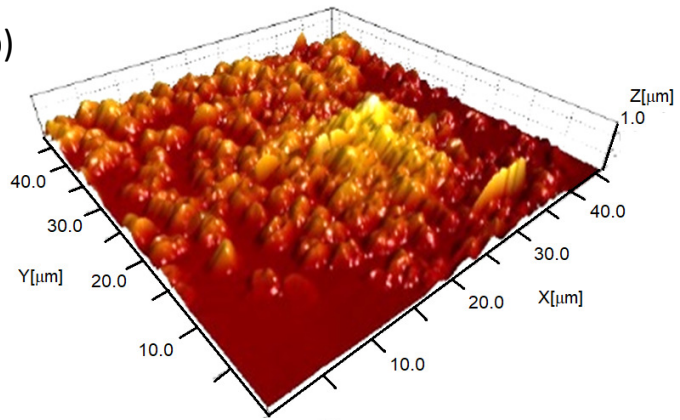

d)

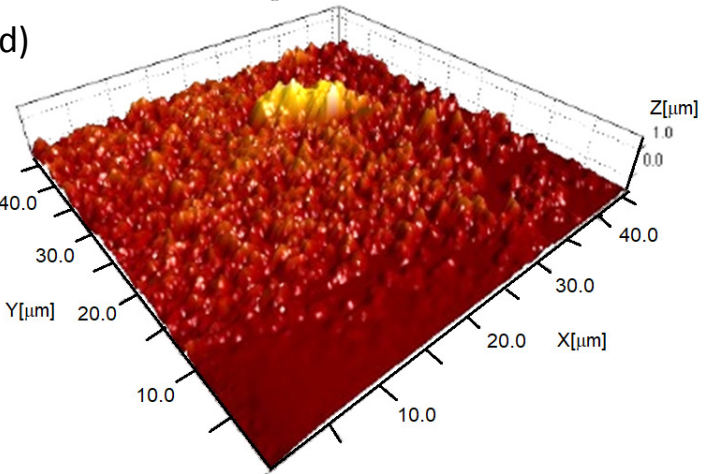

Fig.-2: AFM micrographs (a) Substrate, (b) S1, (c) S2 and (d) S3.

The topography of the substrate is shown in Figure-2a. A somewhat homogeneous surface is observed with some imperfections originated in the process of polishing and conditioning to support the coatings. In addition to evaluating the topography, the AFM technique allows determining the surface roughness values of each of the samples studied. As for the roughness values as a function of the coatings obtained at spin speeds of $1500 \mathrm{rpm}, 2500 \mathrm{rpm}$ and $4000 \mathrm{rpm}$, it was found that for coatings S3 a surface roughness value of $154.3 \pm 5.2 \mathrm{~nm}$ was obtained. With respect to the films $\mathrm{S} 2$, marked changes are observed. The roughness value is $243.5 \pm 3.5 \mathrm{~nm}$. At a spin speed of $1500 \mathrm{rpm}(\mathrm{S} 1)$, it is possible to state, that the highest values of roughness due to the irregularity of the surface are presented; A value of $318.56 \pm 8.1 \mathrm{~nm}$ was determined. The trends in the roughness values found are directly related to the spin speeds applied for the shaping of the coatings. The spin-coating technique establishes that low spin speeds generate thicker films and, depending on the results, rougher films. High spin speeds allow the production of thin films and more homogeneous. Finally, the roughness of the substrate 316L (Figure-3a) with a value of $41.5 \pm 9.2 \mathrm{~nm}$ is reported. The differences between the roughness values of the substrate and in each of the films studied, evidence the growth of coating on the substrate. When comparing the surface behaviors of the films and the substrate (Figure-2) an appreciable variation in the topography is observed. The coatings have fairly 
rough surfaces as a result of the growth of $\mathrm{Bi}$ and $\mathrm{Si}$ oxides. Granular growths of the oxides are also observed whose size varies according to the speed with which the films were confirmed.

According to AFM images, a more homogeneous behavior is favored in coatings at $4000 \mathrm{rpm}$ (Figure-2d). Only coatings obtained at $1500 \mathrm{rpm}$ are grains of oxides in dispersed form. In general, as the spin speed increases, the pellets are more homogeneous ${ }^{18}$.

The grain size distributions for the coatings were also determined. At S1 coatings (Figure-2b) a grain size arrangement ranging from $0.3 \mu \mathrm{m}$ to $3.8 \mu \mathrm{m}$ is displayed. For coatings S2 (Figure-2c), the granulametry ranges from $0.25 \mu \mathrm{m}$ to $1.50 \mu \mathrm{m}$. Regarding the grain size distributions for the coatings S3 (Figure-2d) it is possible to state that the particle size distribution is between $0.1 \mu \mathrm{m}$ and $1 \mu \mathrm{m}$.

The results of the characterization of the films, allow highlighting the impact of the spin speed in the grain size distribution of the films, ie, lower grain sizes were obtained for spin speeds of $4000 \mathrm{rpm}$. At low spin speeds, in the case $1500 \mathrm{rpm}$, a larger granulometric size is evidenced.

Figure-3 shows the Nyquist diagrams for the coatings obtained from stable sols of the $\mathrm{Bi}_{x} \mathrm{Si}_{\mathrm{y}} \mathrm{O}_{\mathrm{z}}$ system at 0.7 molar concentration as a function of the spin speed at which they were obtained: S1, S2 and S3. The working solution used was Ringer's solution, which simulates the conditions of the body fluids.

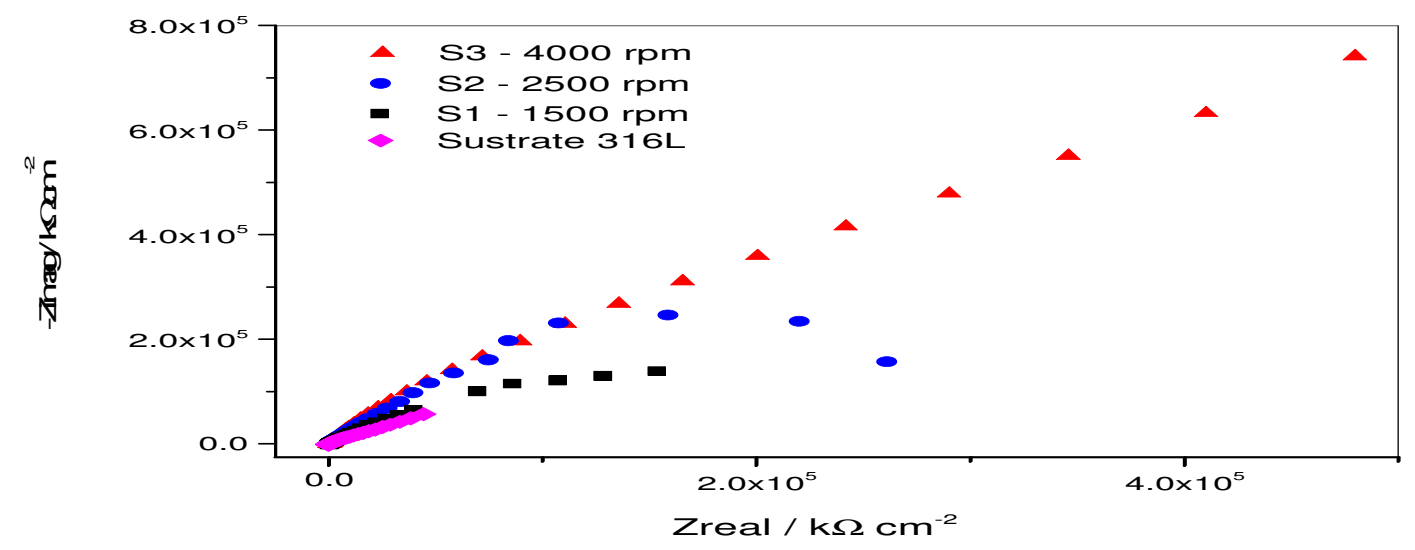

Fig.-3: Nyquist Diagrams

The EIS analysis focuses mainly on the polarization resistance values, $\mathrm{Rp}$. This is the resistance that the coating opposes the passage of ions from solution to a substrate, preventing it from corroding. It is very important to consider that high values of polarization resistance in a coating allow establishing that the films perform as an anticorrosive barrier.

In Figure-3 the same behavior of the Nyquist diagrams is observed, that is, all the graphs are open. This type of behavior demonstrates the existence of high values in the resistance to the polarization and, therefore, low rates of corrosion. According to the obtained results, in all the films an open behavior, greater than that registered for the substrate, is observed. This shows that the films deposited on the substrate 316L act as a protective barrier when are in contact with the Ringer's solution, giving higher efficiency for the films S3. Special behavior is shown by the coatings $\mathrm{S} 2$, which does not act in an efficient way in protection, observing a dome. This can be explained by the possible growth of micropores or microcracks in the coating caused by the accumulation of $\mathrm{Si}$ and $\mathrm{Bi}$ oxides in the sintering process.

The behaviors described in Figure-3 are modeled with the equivalent circuit shown in Figure-4. This circuit relates to a metallic substrate coated with layers of ceramic material. It consists of the following elements: Rsol, the resistance of the solution, corresponds to the resistance offered by the working solution, in this case Ringer's solution. Rpo, polarization resistance. Cc, constant phase element of the coating or porous outer layer. Ccor constant phase element representing the double layer of Helmholtz. Rcor resistance of the ceramic coating or porous outer layer. Rsb and Csb correspond to the characteristics of the substrate. The values of each of the parameters or constituent elements of the equivalent circuit for each of the coatings 
studied are recorded in Table-3. From the information given in these tables an average value is established for the resistance to the working solution, in this case Ringer's solution, $245 \pm 5 \Omega$.

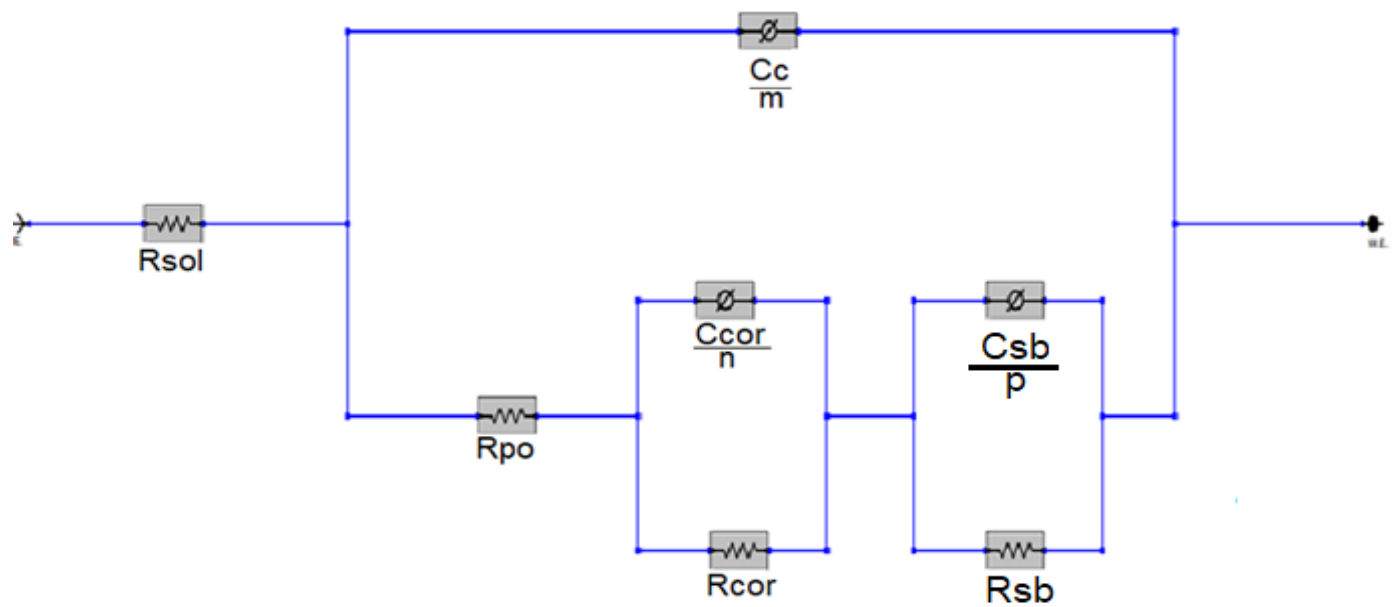

Fig.-4: an Equivalent electrical circuit for $\mathrm{Bi}_{x} \mathrm{Si}_{y} \mathrm{O}_{z}$ system films.

Table-3: Equivalent circuit parameter values for the films.

\begin{tabular}{l|l|l|l|l|l|l|c|c|c|c}
\hline Sample & $\begin{array}{c}\text { Rsol } \\
\left(\Omega \mathrm{cm}^{2}\right)\end{array}$ & $\begin{array}{c}\text { Rpo } \\
\left(\Omega \mathrm{cm}^{2}\right)\end{array}$ & $\begin{array}{c}\text { Rco } \\
\left(\Omega \mathrm{cm}^{2}\right)\end{array}$ & $\begin{array}{c}\text { Ccor } \\
\left.(\mu \mathrm{F} \mathrm{cm})^{-2}\right)\end{array}$ & $\mathrm{n}$ & $\left.\begin{array}{c}\mathrm{Cc} \\
(\mu \mathrm{Fcm}\end{array} \mathrm{Fc}^{-2}\right)$ & $\begin{array}{c}\mathrm{m} \\
\left(\mathrm{x} 10^{-1}\right)\end{array}$ & $\begin{array}{c}\text { Csb } \\
\left.(\mu \mathrm{Fcm})^{-2}\right)\end{array}$ & $\mathrm{p}$ & $\begin{array}{c}\text { Rsb } \\
\left(\Omega \mathrm{cm}^{2}\right)\end{array}$ \\
\hline S1 & 236 & $3.8 \times 10^{6}$ & 89.20 & $5.4 \times 10^{-3}$ & $8.4 \times 10^{-1}$ & $2.8 \times 10^{-7}$ & 9.8 & $4.9 \times 10^{-5}$ & 7.1 & $3.9 \times 10^{5}$ \\
\hline S2 & 250 & $2.7 \times 10^{5}$ & $9.6 \times 10^{3}$ & $1.4 \times 10^{-3}$ & $7.3 \times 10^{-5}$ & $3.2 \times 10^{-3}$ & 8.1 & $2.0 \times 10^{-7}$ & 5.3 & $8.7 \times 10^{5}$ \\
\hline S3 & 249 & $1.1 \times 10^{8}$ & 5.156 & $1.3 \times 10^{-3}$ & $6.1 \times 10^{-1}$ & $1.1 \times 10^{-3}$ & 8.7 & $1.4 \times 10^{-3}$ & 2.1 & $2.9 \times 10^{8}$ \\
\hline
\end{tabular}

Figure-5 shows the equivalent circuit for the uncoated substrate. Rsol, is the resistance of the working solution; Rpo, resistance to polarization; Cc, an element of constant phase and Rco, resistance to corrosion. The values of each parameter are recorded in Table- 4 .

Table-4: Equivalent circuit parameter values for substrate 316L.

\begin{tabular}{c|c|c|c|c|c|c|c}
\hline Sample & $\begin{array}{c}\text { Rsol } \\
\left(\Omega \mathrm{m}^{2}\right)\end{array}$ & $\begin{array}{c}\text { Rpo } \\
\left(\Omega \mathrm{cm}^{2}\right)\end{array}$ & $\begin{array}{c}\mathrm{Cc} \\
\left.(\mu \mathrm{Fcm})^{-2}\right)\end{array}$ & $\mathrm{n}$ & $\begin{array}{c}\text { Rcor } \\
\left(\Omega \mathrm{cm}^{2}\right)\end{array}$ & $\begin{array}{c}\text { Ccor } \\
\left.(\mu \mathrm{F} \mathrm{cm})^{-2}\right)\end{array}$ & $\mathrm{m}$ \\
\hline 316L & 220 & 45.8 & $15.3 \times 10^{-6}$ & $910.6 \times 10^{-3}$ & $2.69 \times 10^{9}$ & $5.42 \times 10^{-6}$ & $396.8 \times 10^{-3}$ \\
\hline
\end{tabular}

To complement this study, the porosity percentage of the coatings of the $\mathrm{Bi}_{\mathrm{x}} \mathrm{Si}_{\mathrm{y}} \mathrm{O}_{\mathrm{z}}$ system is estimated by equation- $1,{ }^{21,22}$.

$$
P f_{R p}=\frac{R_{p, u}}{R_{p, r-u}}
$$

Where $P f_{R p}$ is the percentage of porosity of the coating in terms of the Substrate bias Resistance $R_{p, u}$, and the polarization resistance of the film, $R_{p, r-u}$. It was found that the percentage of porosity for all coatings of the $\mathrm{Bi}_{\mathrm{x}} \mathrm{Si}_{\mathrm{y}} \mathrm{O}_{\mathrm{z}}$ system is very low, about $1 \%$.

The graphs of Fig.- 6 reveal the Tafel diagrams of the $\mathrm{Bi}_{\mathrm{x}} \mathrm{Si}_{\mathrm{y}} \mathrm{O}_{\mathrm{z}}$ system for coatings $\mathrm{S} 1$, S2 and S3 respectively, and the comparison with respect to the AISI/SAE 316L steel substrate. The change of the corrosion potentials of the coatings with respect to the corrosion potential of the substrate is observed. The corrosion potential takes more positive values with respect to the substrate ${ }^{23,24}$. It is noteworthy that some velocities present a better anticorrosive performance than others, this is concluded when comparing the results of corrosion potential values and corrosion current for the studied films, as shown in Table-5.

The corrosion potential values for the substrate and for each film of the $\mathrm{Bi}_{x} \mathrm{Si}_{y} \mathrm{O}_{z}$ system are consolidated in Table-5. Knowing the trend of the parameters mentioned above will allow knowing the behavior of the substrate-coating interface in each case. 


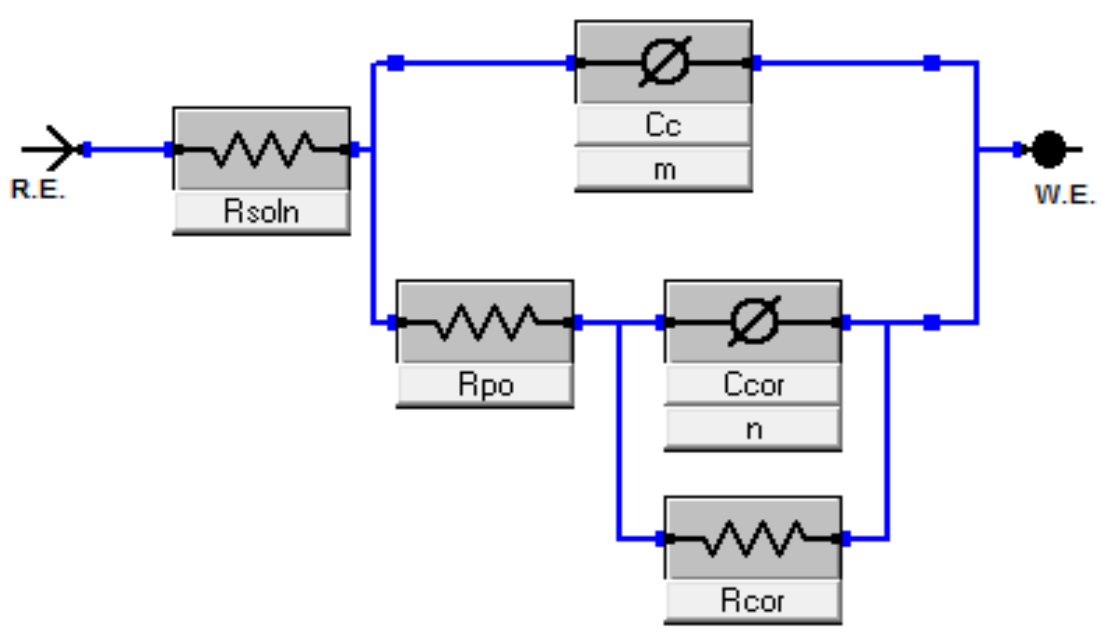

Fig.-5: Equivalent circuit for 316L steel substrate

With respect to the corrosion currents, it is indicated that these values are lower with respect to the information found for the uncoated substrate. The values of the corrosion potentials and the corrosion currents for the coatings as a function of the spin speed with which they were formed are recorded in Table5.

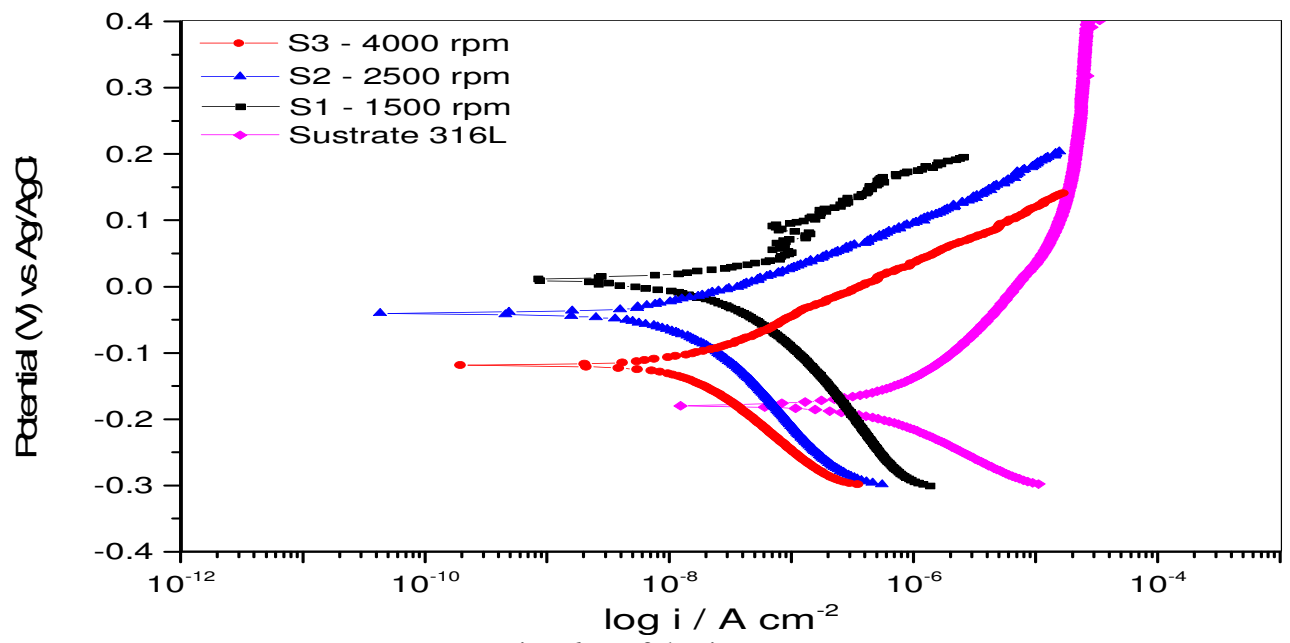

Fig.-6: Tafel Diagrams

From Table-5 in addition to the values of the anodic and cathodic slopes, corrosion potentials and currents are recorded the corrosion rate values for the formed coatings S1, S2 and S3, respectively. In relation to the information indicated for the corrosion rates it is possible to state that all the films in greater or lesser action act as barriers that decrease the speed of corrosion with respect to the uncoated substrate $316 \mathrm{~L}$. The difference between the corrosion rate values between the values found in the films and the substrate are two orders of magnitude with respect to the target.

Table-5: Values of the parameters according to the Tafel polarization curves for the films.

\begin{tabular}{c|c|c|c|c|c}
\hline Sample & $\begin{array}{c}\beta \text { anodic } \\
(\mathrm{mV} / \text { decade })\end{array}$ & $\begin{array}{c}\beta \text { cathodic } \\
(\mathrm{mV} / \mathrm{decade})\end{array}$ & $\begin{array}{c}\text { Icor } \\
(\mathrm{nA})\end{array}$ & $\begin{array}{c}\text { Ecor } \\
(\mathrm{mV} \text { vs Ag/AgCl })\end{array}$ & $\begin{array}{c}\text { Corrosion rate } \\
(\mathrm{mpy})\end{array}$ \\
\hline S1 & 130.12 & 196.6 & 33.10 & 7.55 & $15.10 \times 10^{-3}$ \\
\hline S2 & 69.30 & 167.1 & 11.10 & -41.40 & $5.05 \times 10^{-3}$ \\
\hline S3 & 90.80 & 176.1 & 17.70 & -120.01 & $8.06 \times 10^{-3}$ \\
\hline
\end{tabular}


It is also possible to determine the percentage of protective effect of the coatings of the $\mathrm{Bi}_{\mathrm{x}} \mathrm{Si}_{\mathrm{y}} \mathrm{O}_{\mathrm{z}}$ system as a function of spin velocities, as indicated in Equation $2^{21,22}$ :

$$
E f(\%)=\left(\frac{I_{\text {corrs }}-I_{\text {corr }}}{I_{\text {corrs }}}\right) \times 100
$$

Where $I_{\text {corr }}$ is the corrosion current density of the uncoated substrate and $I_{\text {corrf }}$ is the corrosion current density of the coated substrate.

Table- 6 shows the values for the percentage of protective effectiveness. From the calculations, it is identified that all films studied to provide a percentage of protective effectiveness greater than $95 \%$.

Table-6: Protective effectiveness factor values

\begin{tabular}{c|c}
\hline Sample & $E f(\%)$ \\
\hline S1 & $96.06 \pm 1.36$ \\
\hline S2 & $98.68 \pm 1.08$ \\
\hline S3 & $97.89 \pm 0.19$ \\
\hline
\end{tabular}

In general terms, the coatings studied show corrosion resistance and good protective efficacy. This behavior is probably due to the low oxidation of $\mathrm{Bi}$ and $\mathrm{Si}$ in the sintering process and to the good adhesion of the films to the substrate ${ }^{23,24}$. It can also be attributed to the morphological influence in the films concluding that they have a homogeneous structure with small grains but present some pores allowing the working electrolyte to pass through the interface substrate coating and lead to possible delamination of the Film ${ }^{25,26}$. In the evaluated system (film-substrate), there is a cathodic reaction on the surface of the coating and an anodic reaction produced on the surface of the substrate. The results also show that the application of the $\mathrm{Bi}_{x} \mathrm{Si}_{y} \mathrm{O}_{z}$ coating, imparts thermodynamic stability to the surface increasing the protection potential of the system $^{27,28}$.

Table-7: Characteristic peaks of the $\mathrm{Bi}_{24} \mathrm{O}_{40} \mathrm{Si}_{2}$.

\begin{tabular}{c|c|c}
\hline Peak & $\begin{array}{c}\text { Position } \\
\left({ }^{\circ} 2 \theta\right)\end{array}$ & $\begin{array}{c}\text { d-reticular } \\
(\AA)\end{array}$ \\
\hline 1 & 27.685 & 3.219 \\
\hline 2 & 32.921 & 2.718 \\
\hline 3 & 43.610 & 2.073 \\
\hline 4 & 50.828 & 1.7949 \\
\hline 5 & 76.2042 & 1.2483 \\
\hline 6 & 77.566 & 1.2297 \\
\hline
\end{tabular}

Figure-7 shows the diffraction patterns, taken at an angle, for the coatings. The diffractograms show the structure sillenite $\left(\mathrm{Bi}_{24} \mathrm{O}_{40} \mathrm{Si}_{2}\right)$ found in all coatings, according to standard chart PDF 98-002-5849. Diffraction patterns show similar behavior due to the sintering conditions to which the films were subjected in which the heating rate, temperature and time were matched constant. Table- 7 shows the positions of the characteristic peaks and distance reticular of the sillenite.

\section{CONCLUSION}

The SEM and AFM techniques allowed to analyze the topography of the coatings. The study shows surfaces with high roughness related to the growth of silicon oxides and bismuth oxides in the sintering process. The results of corrosion evaluation by the characterization by EIS techniques and polarization potentiodynamic curves show that all the coatings improve, according to the spin speed, the anticorrosive response of the substrate. It was evidenced a low percentage of porosity and high percentage of anticorrosive effectiveness in the coatings.

There is a direct influence of the spin speed on the anticorrosive properties, roughness and thickness of the coatings. 


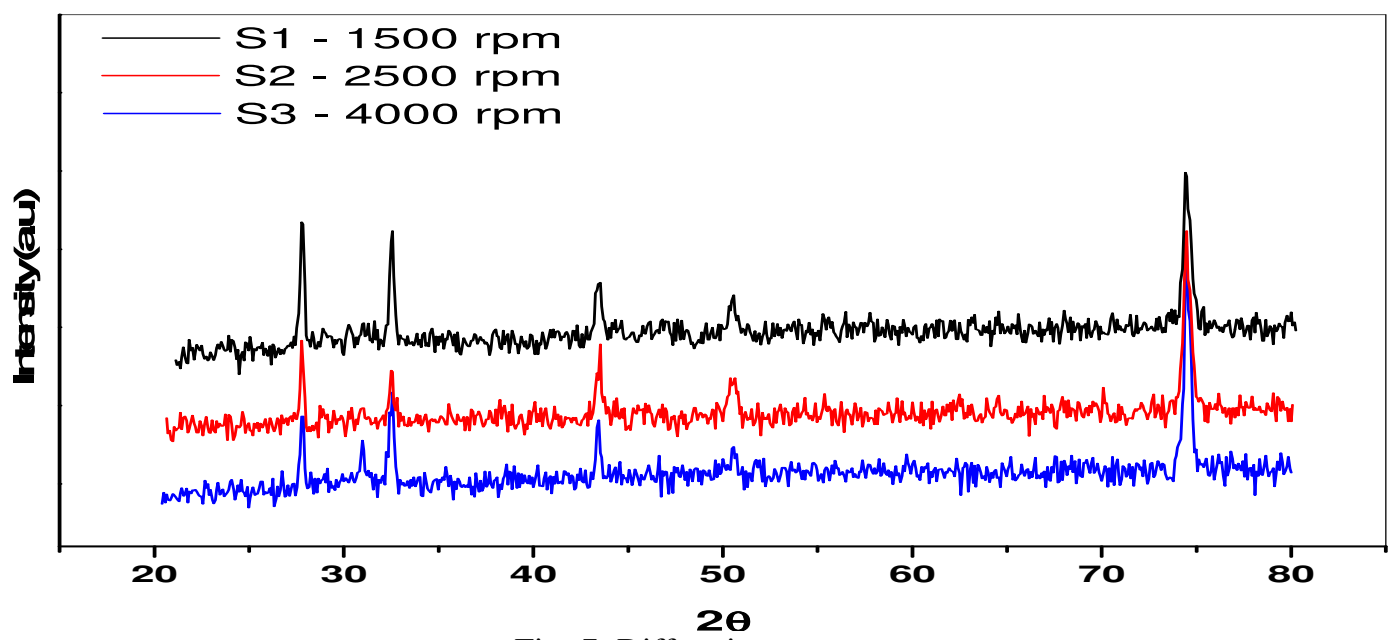

Fig.-7: Diffraction patterns

ACKNOWLEDGEMENT

J. Bautista at Universidad Francisco de Paula Santander, San José de Cúcuta Colombia.

Author Contributions: Willian Aperador performed the obtaining coatings; Jorge Bautista worked in measurements in SEM, AFM and XRD and performed the interpretation of the data and the respective analysis. John Jairo Olaya performed measurements corrosion tests performed the interpretation of the data.

\section{REFERENCES}

1. A. Veber, Š. Kunej and D. Suvorov, Ceram. Int., 36(1), 245 (2010), DOI: 10.1016/j.ceramint.2009.07.024

2. D. R. Uhlmann, G. Teowee and J. Boulto, J. Sol-gel Sci. Tech, 8, 113 (1997), DOI:10.1016/S00223093(97)00162-2

3. T. Sathiyapriya and G. Rathika, Rasayan J. Chem., 10(4), 1462 (2017), DOI: 10.7324/RJC.2017.1041947.

4. G. Ramanathan and K.R. Murali, Rasayan J. Chem., 10(3), $700 \quad$ (2017), DOI:10.7324/RJC.2017.1031715.

5. S. Inbakumar and P. M. Andavan, Rasayan J. Chem., 10(2), 507 (2017), DOI:10.7324/RJC.2017.1021725.

6. http://www.pennstainless.com/stainless-grades/300-series-stainless-steel/3161-stainless-steel/

7. M. Fontana, Corrosion Engineering, McGraw-Hill, Inc., Boston, p. 85-89(1987).

8. L. Fedrizzi, F. Rodriguez, S. Rossi and F. Deflorian, Electrochim. Acta, 46, 3715 (2001), DOI: 10.1016/S0013-4686(01)00653-3

9. M. Catauro, F. Bollino, R. Giovanardi, P. Veronesi. Mater Sci Eng C Mater Biol Appl. 74501 (2017), DOI:10.1016/j.msec.2016.12.046.1.

10. T. Sugama, J. Coat. Technol., 2, 8 (2005), DOI:10.1007/BF02774594

11. H. Cheraghia, M. Shahmiria and Z. Sadeghianb, Thin Solid Films, 522, 289 (2012), DOI:10.1016/j.tsf.2012.07.125

12. D. Sidane, D. Chicot and S. Yalaa, Thin Solid Films, 593, 220 (2015), DOI:10.1016/j.tsf.2015.09.037

13. E. Salahinejad, M. Hadianfard, D. Macdonald, M. Mozafari, D. Vashaee and L. Tayebi, Mater. Lett., 97, 162 (2013), DOI:10.1016/j.matlet.2013.01.111

14. E. Coy, L. Yate, D. P. Valencia, W. Aperador, K. Siuzdak, ACS Applied Materials \& Interfaces, 9 , 30872 (2017), DOI: 10.1021/acsami.7b10317

15. D. Wang and G.P. Bierwagen, Prog. Org. Coat., 64, 4 (2009), DOI:10.1016/j.porgcoat.2008.08.010 
RASĀYAN J. Chem.

Vol. 11 | No. 2 |597-607 | April - June | 2018

16. H. Weidong, Q. Wei, W. Xiaohong, D. Xianbo, C. Long and J. Zhaohua, Thin Solid Films, 515, 13 (2007), DOI:10.1016/j.tsf.2007.01.031

17. W. Xiaohong, Q. Wei and H. Weidong, J. Mol. Catal. A: Chem., 261(2), 167 (2007).

18. F. L. Alférez Vega, J.J. Olaya and J. Bautista Ruiz, Ceram. Int., 44, 2 (2018), DOI:10.1016/j.ceramint.2017.10.161

19. A. Rajabi-Zamani, A. Behnamghader and A. Kazemzadeh, Mater. Sci. Eng. C., 28(8), 1326 (2008), DOI:10.1016/j.msec.2008.02.001

20. W. Feng, L. Mu-sen, L. Yu-peng and Q. Yong-xin, Mater. Lett, 59(1), 916 (2005), DOI:10.1016/j.matlet.2004.08.041

21. D. Sidane, D. Chicot, S. Yala, S. Ziani and H. Khrireddine, Thin Solid Films, 593, 71 (2015), DOI:10.1016/j.tsf.2015.09.037

22. K. L. Chang, S. C. Chung and S. Lai, Appl. Surf. Sci., 236(1-4), 406 (2004), DOI:10.1016/j.apsusc.2004.05.024

23. H. Altun and S. Sen, Surf. Coat. Technol., 197(2-3), 193 (2005), DOI:10.1016/j.surfcoat.2004.06.001

24. J. Titz, G. H. Wagner, H. Spähn, M. Ebert, K. Jüttner, W. J. Lorenz, Corrosion, 46 (3), 221 (1990), DOI: $10.5006 / 1.3585095$

25. Y. Yoo, D. Le and S. Kim, Thin Solid Films, 516(11), 3586 (2008), DOI:10.1016/j.tsf.2007.08.112

26. L. Dimate, J. Olaya, J. Alfonso, Ingeniería y Desarrollo, 35, 17 (2017), DOI:10.14482/inde.35.1.8941

27. P. Guzmán, L. Yate, M. Sandoval, J. Caballero, Materials, 10, 842 (2017), DOI:10.3390/ma10080842

28. L. Yate, L. E. Coy, D. Gregurec, W. Aperador, S. E. Moya, and G. Wang, ACS Appl. Mater. Interfaces 7, 6351 (2015), DOI: 10.1021/acsami.5b01193

[RJC-2075/2018] 